THE POSTGRADUATE

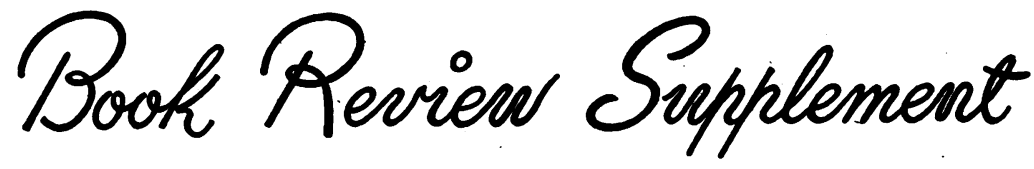

\section{REPORT OF THE MEDICAL RESEARCH COUNCIL FOR THE YEAR 1951-1952}

Pp. iv + 24I. London: H.M.S.O. I953. 6s. 6d.

This report includes a summary of the work carried out in the separate research establishments controlled by the Medical Research Council; also various statistical facts such as a list of the members of the Council and its principal committees and 66 pages are devoted to a list of the publications by the members of the Council staff.

\section{DISEASES OF THE THROAT, NOSE AND EAR}

Edited by F. W. Watkyn-Thomas, F.R.C.S. Pp. $\mathrm{xi}+880$, with 367 illustrations, 22 in colour. London: H. K. Lewis \& Co. I953. £5 ros.

The arrival of yet another new textbook on Diseases of the Ear, Nose and Throat may at first seem unnecessary. This book, however, replaces the out-dated one written by Herbert Tilley, and in so doing its editor has produced what is undoubtedly a really first-class work.

There are many noteworthy points. It is a textbook of one volume, containing an amazing amount of information suitable as the groundwork for the Final F.R.C.S. (E.N.T.) examination, as well as being a book of reference for the practising surgeon. The editor has marshalled a well-balanced team of colleagues, mostly from University College Hospital, who have followed the same pleasant, readable style of writing, with interesting reminiscences. All contributors have cut out much old and unnecessary data, making room for a vast amount of detail concerning present-day methods and opinions; the fullness of the index with references to these details is remarkable.

Several subjects not usually discussed fully in other textbooks of this specialty have been included. Outstanding in this category are the chapters on plastic techniques, the management of deafness and aviation otology. Many subjects are dealt with from a delightfully fresh aspect, with older opinions mentioned briefly. The apportioning of space is rationalized, with subjects like endoscopy occupying a brief though excellent section..

The editor has wisely borrowed many excellent plates and diagrams from the best sources, so that, with the few exceptions mentioned below, the standard of illustration is very high. Moreover, it $\frac{\mathrm{O}}{3}$ is a pleasure to see how well the proofs of a first edition have been corrected, as one misprint only was noted.

It is always possible to criticize any textbook. The poor colouration of the diagrams illustrating $\mathrm{N}_{\mathrm{N}}$ laryngeal conditions is very striking and far below $N$ standard; the sketch illustrating adenoids is ofo doubtful use. There are several statements which_ differ in opinion very strongly from that usually accepted, particularly by examiners. Examples are some of the ' absolute indications ' for tonsillectomy응 and the incision in the pharynx of a tuberculous $\mathbb{Q}$ retropharyngeal abscess. Lastly there are stat $8-\overrightarrow{0}$ ments which express controversial opinion withouter other views being mentioned. Examples of these. are that obstruction of nasal respiration is the intvariable cause of maldevelopment of maxilla, hard palate and teeth; a nice picture of orthodontic abnormalities seems to suggest that they could beg the cause rather than the effect of mouth breathing and large adenoids. Also in this category are the statements that the electric naso pharyngoscope can $\overrightarrow{\bar{O}}$ give a view of the "whole of the post-nasal space, 3 and that the sphenoid sinus is ' never' the seat of? primary malignant disease.

The above remarks in no way detract from the general excellence and usefulness of this book. Although its price appears rather formidable, it:seems an essential acquisition both for all post- 3 . graduates taking examinations and for practising otorhinolaryngologists.

\section{HISTOLOGY}

By A. W. HaM, M.B., F.R.S.C. 2nd Edition Pp. $x i x+866$, with 518 illustrations, 7 in colour $N$ London: J. B. Lippincott Company. 1953. 80s.

It is not quite three years since the first edition 0 of Professor Ham's 'Histology' was reviewed in this journal. The fact that a new edition is called for so soon is evidence not only of rapid advance in the science of histology, but also of the well-deserved popularity which the book has won for itself despite? its high price.

Its general plan and character is substantially un $\frac{T}{-}$ altered, though additions and modifications have्ष 